\title{
Aa. Vv., L'identité, «Questes. Bulletin des jeunes chercheurs médiévistes», 24
}

\section{Maria Colombo Timelli}

\section{(2) OpenEdition}

1 Journals

Édition électronique

URL : http://journals.openedition.org/studifrancesi/1058

DOI : 10.4000/studifrancesi. 1058

ISSN : 2427-5856

Éditeur

Rosenberg \& Sellier

Édition imprimée

Date de publication : 1 novembre 2014

Pagination : 562-563

ISSN : 0039-2944

\section{Référence électronique}

Maria Colombo Timelli, «Aa. Vv., L'identité, «Questes. Bulletin des jeunes chercheurs médiévistes», 24

», Studi Francesi [En ligne], 174 (LVIII | III) | 2014, mis en ligne le 01 novembre 2014, consulté le 18 septembre 2020. URL : http://journals.openedition.org/studifrancesi/1058 ; DOI : https://doi.org/ 10.4000/studifrancesi. 1058

Ce document a été généré automatiquement le 18 septembre 2020.

\section{(c) (†) $\odot$}

Studi Francesi è distribuita con Licenza Creative Commons Attribuzione - Non commerciale - Non opere derivate 4.0 Internazionale. 


\title{
Aa. Vv., L'identité, «Questes. Bulletin des jeunes chercheurs médiévistes», 24
}

\author{
Maria Colombo Timelli
}

\section{RÉFÉRENCE}

L'identité, «Questes. Bulletin des jeunes chercheurs médiévistes», 24, 2012, pp. 123.

1 Deux articles de ce fascicule concernent la littérature médiévale. Celui d'émILIE DESCHELLETTE (L'identité à l'épreuve du mythe: la fabrique des origines, d'Énéas à Brutus, pp. 66-84) concerne une quête d'identité collective, à savoir la recherche des origines antiques des Bretons dans l'œuvre de Geoffroy de Monmouth et de Wace. Si Brutus est un personnage ambivalent, en même temps condamné à l'exil et prédestiné à un destin glorieux, il constitue pour les Bretons l'ancêtre illustre qui garantit une continuité identitaire allant de Troie à la Grande Bretagne en passant par Rome, à savoir la translatio imperii si chère à la culture de l'Occident médiéval. Dans le deuxième, SERVANE MICHEL vise à montrer le caractère foncièrement ambigu de certains «méchants» du Lancelot en prose. Parmi ceux-ci, Claudas, ennemi du monde arthurien, n'incarne cependant pas le mal absolu; personnage condamnable moralement, mais aussi doué d'une prouesse exceptionnelle, il est l'objet de points de vue différents: en particulier, à travers la modalité du discours intérieur le romancier nous donne accès à ses motivations, ce qui contribue à brouiller son identité morale (L'impossible identité narrative de Claudas, l'admirable méchant du Lancelot en prose, pp. 96-111). 